\title{
Assessing the full costs of floodplain buyouts
}

\author{
William Curran-Groome ${ }^{1}$ (D) $\cdot$ Hallee Haygood $^{1} \cdot$ Miyuki Hino $^{1}$ (D) \\ Todd K. BenDor ${ }^{1}$ (D) - David Salvesen ${ }^{2}$
}

Received: 24 February 2021 / Accepted: 14 July 2021/ Published online: 14 September 2021

(C) The Author(s), under exclusive licence to Springer Nature B.V. 2021

\begin{abstract}
Given projected increases in flood damages, managed retreat strategies are likely to become more widespread. Voluntary buyouts, where governments acquire flooddamaged properties and return the sites to open space, have been the primary form of federally funded retreat in the USA to date. However, little attention has been paid to the cost structure of buyout projects. Using a transaction cost framework, we analyze the costs of activities that comprise floodplain buyouts. Federal data do not distinguish transaction costs, but they do suggest that the cost of purchasing properties often accounts for $80 \%$ or less of total project costs. Through a systematic review ( $n=1103$ publications) and an analysis of government budgets (across $n=859$ jurisdiction-years), we find limited sources with relevant cost information, none of which reports transaction costs. The absence of activity-level cost data inhibits more targeted policy reform to support community-driven and efficient buyout programs. Better data collection and reporting can inform more impactful and equitable buyout policy.
\end{abstract}

Keywords Floodplain buyouts · Climate adaptation · Hazard mitigation · Environmental finance Flood policy $\cdot$ Municipal finance

\section{Introduction}

Average annual, flood-related damages in the USA have increased significantly over time (Davenport et al. 2021). This trend, combined with population growth patterns and a variety of negative predicted effects of climate change (Wing et al. 2018), has contributed

Todd K. BenDor

bendor@unc.edu

1 Department of City and Regional Planning, University of North Carolina at Chapel Hill, New East Building, Campus Box \#3140, Chapel Hill, NC 27599-3140, USA

2 Institute for the Environment, University of North Carolina at Chapel Hill, 100 Europa Dr Suite 490, Chapel Hill, NC 27517, USA 
to a growing consensus that managed retreat will be a necessary component of flood mitigation strategies going forward (Reidmiller et al. 2018). To date, floodplain buyouts ${ }^{1}$ have constituted the primary federally funded approach to managed retreat in the USA (Dyckman et al. 2014). In buyout programs, governments purchase flood-prone properties from willing sellers, usually restoring the land to some sort of open space. Property owners receive compensation for their flood-damaged homes, while the removal of structures from the floodplain reduces future flood damages and emergency response burdens (BenDor et al. 2020; Siders 2013a).

Efforts to assess and improve floodplain buyouts require an understanding of their full costs across the different levels of government involved, as is true of other devolved funding structures (Feiock 2001). While both federal agencies (e.g., FEMA 2013; FEMA 2021a) and academic researchers (e.g., Tate et al. 2016; Nelson and Camp 2020) have undertaken benefit-cost studies, these studies often conflate property purchase costs with total project costs, omit certain cost categories, or overlook the distribution of costs among actors. These data gaps are problematic for several reasons. First, non-purchase costs associated with buyouts may be large due to the information-sharing, planning, and negotiation involved (Meyer et al. 2012). An analysis of transfer of development rights (TDR) programs, which parallel floodplain buyouts in that both entail the transfer of real property rights, found that meeting administrative requirements, holding public meetings, finalizing contracts, and other non-purchase costs accounted for between 13 and 21\% of total costs (Shahab et al. 2018).

Second, non-purchase activities (e.g., communication, planning) are critical for enabling community-driven buyout programs, but it is unclear how much human and financial capital is dedicated to those activities across different buyout projects (Siders 2018). Understanding the costs of non-purchase activities can help ensure that such activities are adequately funded. Thus, the lack of information about costs incurred on various floodplain buyout activities across federal, state, and local actors impedes efforts to strike a balance between streamlining buyout processes while supporting critical engagement activities.

In this study, we aim to assess the full costs associated with buyout projects, in particular those costs imposed by federal policy requirements. We begin by briefly covering the existing federal funding structures for floodplain buyout projects, and then define a typology to classify costs of buyout activities as production costs, transaction costs, or transaction costs imposed by federal policy. We then explore three sources of data to quantify the activity-level costs incurred in a typical buyout project in the USA: administrative records of FEMA-funded hazard mitigation projects; the peer-reviewed and gray literatures; and budget documents from a sample of local, county, and state governments that have implemented floodplain buyouts.

\footnotetext{
${ }^{1}$ We use the term "buyout" throughout this paper to refer both to acquisition projects where property owners are offered pre-flood fair market values (FMVs) and acquisition projects where property owners are offered postflood FMVs. We do not distinguish between projects that prohibit future development and those that allow redevelopment. In contrast, HUD distinguishes between these two models, referring to the former as a "buyout" and the latter as an "acquisition"; FEMA only funds the former, which it refers to as an "acquisition and demolition" project (HUD 2019; FEMA 2015). Because FEMA funding accounts for such a significant share of buyout funding (Mach et al. 2019; Peterson et al. 2020), buyout properties that are redeveloped are relatively uncommon.
} 


\section{Background}

\subsection{Structure of federally funded buyouts in the USA}

The majority of buyout funding in the USA comes from federal government sources, including the Federal Emergency Management Agency's (FEMA) Hazard Mitigation Assistance programs - in particular the Hazard Mitigation Grant Program (HMGP) - and the Department of Housing and Urban Development's (HUD) Community Development Block Grant Disaster Recovery (CDBG-DR) program (Peterson et al. 2020). These programs, which fund buyouts in addition to other hazard mitigation and disaster recovery efforts, have supported floodplain buyouts for the past three decades (FEMA 2018). Most federal buyout funds require a $25 \%$ non-federal cost match, whereby states, local governments, or other entities (e.g., foundations [e.g., UNC CRC 2018], property owners [e.g., Kummerer 2019]) cover a portion of buyout costs. Some states and local governments also operate their own floodplain buyout programs, which can be funded through stormwater fees, sales tax increments, legislative appropriations, or other sources.

A typical FEMA-funded HMGP buyout project is illustrated in Fig. 1. Under this program, states are the primary recipients for hazard mitigation funding. States work with local governments to compile an application of mitigation-eligible properties, and then send a single, statewide application to FEMA. If awarded, states then take these funds and distribute them to local governments, which interface with property owners and conduct - or contract out - many of the buyout implementation activities. HUD's CDBG-DR program follows a similar general structure wherein federal funds are awarded to states, which often then subgrant funds to local governments for implementation (HUD 2013).

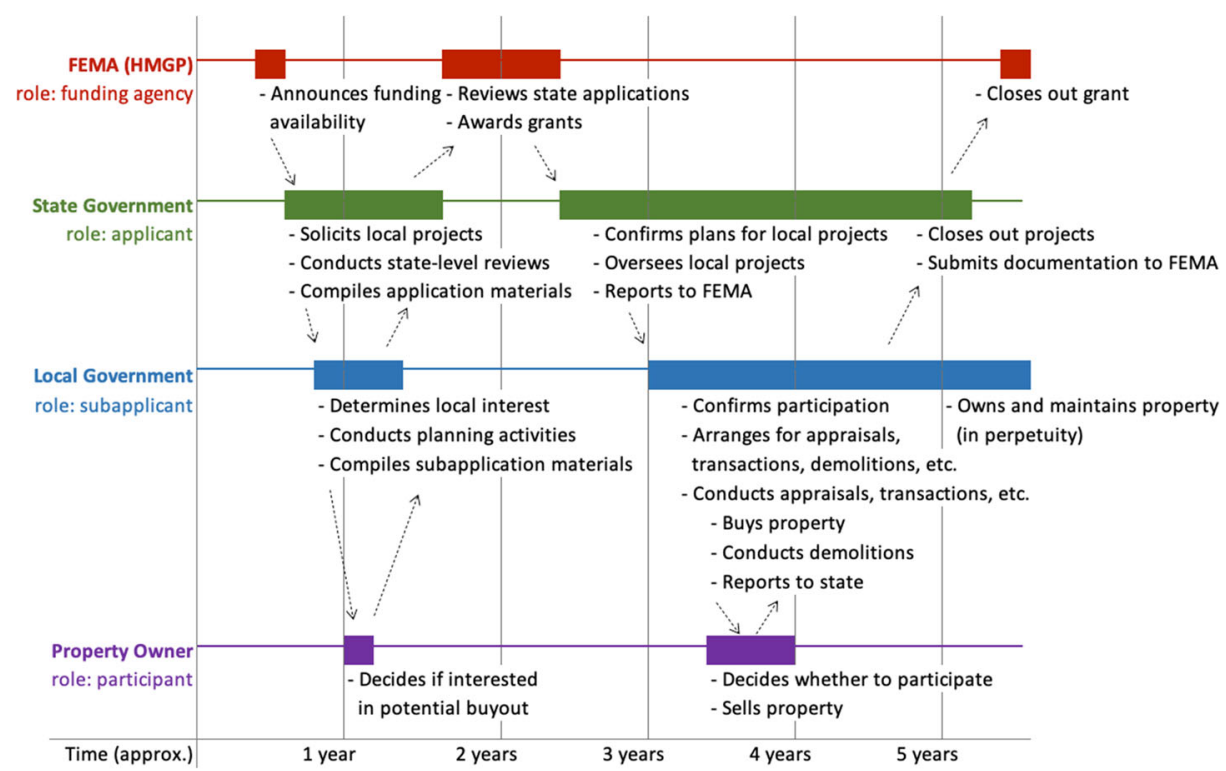

Fig. 1 Timeline of a typical HMGP-funded buyout. Reprinted and adapted with permission from Weber and Moore (2019) 
As depicted by Weber and Moore (2019; Fig. 1), the typical buyout project involves multiple actors engaged in a complex series of sequenced activities. This program structure, which is further complicated by a reactive and irregular cycle of buyout funding (funding is allocated in the wake of major disasters; Martin et al. 2019), may create inefficiencies, including (1) burdensome and overlapping application, reporting, and project management processes between different levels of government and across federal funding agencies (Greer and Binder 2017; Mach et al. 2019; US GAO 2021; Kick et al. 2011); (2) fractured authority across and within local, state, and federal agencies, leading to conflicting guidance and interpretations of project requirements (Fraser et al. 2003; Greer and Binder 2017; Mach et al. 2019; Kick et al. 2011); (3) a need for high levels of staff capacity at the local level (Mach et al. 2019; US GAO 2021; Martin et al. 2019), despite the fact that many buyout projects, and the communities implementing them, are fairly small; and (4) marginal economies of scale as a result of municipal implementation of projects, which often acquire only a single property (the median and mean FEMA-funded buyout projects acquire only three and eleven properties, respectively [FEMA 2020b]).

These structural inefficiencies can burden government staff involved in the buyout funding and implementation pipeline, and they also lead to an extremely drawn-out process; Weber and Moore (2019) found that the median HMGP buyout project takes over 5 years from flooding to project close-out, and CDBG-DR-funded projects appear to be similarly lengthy (Martin et al. 2019). Both required staff time and project duration may have negative implications for property owners and implementing governments.

For property owners, the long, drawn-out process can lead to program attrition, with participants who initially signaled interest in a buyout deciding either to repair their home and remain in place; sell to a third party; or walk away from their property altogether (Binder et al. 2020). Thus, the delay between a flooding event and closings on participants' properties reduces the number of acquired properties, leaving residents at risk of future flooding. Furthermore, delays can lead to residents sustaining additional, subsequent flooding while waiting for buyout offers associated with the initial event, producing compounding health and quality of life concerns. For those residents who do hold out, the length of the buyout process creates an extended period of uncertainty and liminality. Either residents must continue to live in their flood-damaged properties in substandard and potentially unsafe conditions or they must find temporary alternative housing, awaiting a buyout offer that will enable them to move to more permanent housing (Baker et al. 2018). According to a survey conducted a year after Hurricane Harvey struck Texas, $19 \%$ of all respondents - and $27 \%$ of Hispanic respondents and those with incomes under $200 \%$ of the poverty line - reported that their flood-damaged homes remained unsafe to live in (Hamel et al. 2018).

Both for residents who eventually have their properties acquired and for those who are interested but do not receive a buyout, the process also entails time costs. Prospective participants must learn about the details of the particular buyout project and the qualifications required for becoming eligible for a buyout; obtain property records and other required documentation; and navigate legal processes, such as contesting property valuations and completing property deed transfers.

Implementing agencies, both local and state, are also impacted by program attrition. As Binder et al. (2020) note, agencies tend to focus on buyout programs as mitigation tools that can reduce future flood losses and facilitate better land use and infrastructure patterns. Yet, attrition results both in fewer acquired properties - and thus smaller reductions in future flood 
losses - and poorer land use outcomes as a result of "checkerboarding"2 patterns of property acquisition. Technical capacity barriers and administrative burdens associated with applying for and implementing buyout projects may also lead governments either to eschew such programs altogether or to reduce the number of acquisitions they undertake in order to limit this burden (Mach et al. 2019; US GAO 2021; Martin et al. 2019).

\subsection{Defining transaction costs in floodplain buyouts}

Transaction costs, in the context of government programs, have been previously defined as those "costs associated with the design and implementation of public policies" (Meyer et al. 2012). A transaction cost-oriented analysis may be particularly salient to evaluating federally funded buyout programs because it focuses on the structural arrangement of activities - how responsibilities are allocated between different actors and across different levels of the funding hierarchy - and can thus inform efforts to create better structures (Bryson and Ring 1990).

Though they do not use the term "transaction costs," federal funders are concerned about the magnitude of funding devoted to ancillary activities required to implement buyout projects. Both HMGP and CDBG-DR have policies that define and limit "management" and "administrative" costs. HMGP caps the portion of awards that may be spent on "management" costs - such as developing and compiling applications, providing technical assistance, managing grants and reporting, and all other indirect costs - to no more than $10 \%$ of the grant award for states, and no more than an additional 5\% for sub-applicants (FEMA 2020a). CDBG-DR typically caps administrative costs—-such as budget development, monitoring and evaluation, and grant reporting - at $5 \%$ of the total grant amount, with no restrictions on which entities (states or local governments) incur these administrative costs. CDBG-DR also limits "planning and general administration costs," which comprise items such as leased office space and salaries for staff with general oversight responsibilities, to no more than $20 \%$ of the grant award (HUD 2019).

While these policies limit how federal funds are budgeted, they do not necessarily limit how buyout costs are incurred. For example, grantees may shift buyout responsibilities to staff that are not listed on grant budgets in order to avoid exceeding funding limitations, or they may budget staff time under program delivery activities when in fact staff are spending part of that time on administrative or management activities. Furthermore, FEMA's and HUD's funding policies do not require activity-level cost accounting and thus provide little insight into which administrative or management components of buyout projects might be optimal targets for reform.

We begin our investigation of activity-level buyout costs by classifying buyout activities as incurring either "buyout transaction costs," more general transaction costs, or production costs. Following Buitelaar (2004), we operationalize transaction costs by evaluating whether each activity would be necessary given a frictionless market, where information is acquired and property rights exchanged without any cost (North 1990, p. 11). However, because our interest is in transaction costs produced by federal buyout policy, not those resulting from other institutions that create market friction (e.g., requirements for a notary to witness and sign a deed transfer), we classify activities as incurring either "buyout transaction costs" - costs

\footnotetext{
2 "Checkerboarding" refers to a common pattern in buyouts where acquired properties are not clustered. Checkerboarding can preclude efficiencies that local governments might otherwise achieve from discontinuing sewer, water, and road maintenance, leading to areas with scattered buyout properties (BenDor et al. 2020).
} 
resulting from federal funding requirements; general transaction costs - those costs, such as closing costs, that would not occur given a frictionless market, but that would occur even if the buyout were not funded with federal dollars; and production costs - those costs that would occur even in a frictionless market. In Fig. 2, we present the application of this approach to the various buyout activities identified by Weber and Moore (2019).

All of the costs associated with activities preceding the award of grant funds necessarily constitute buyout transaction costs: these activities are purely functions of the structure of the funding mechanism. For the same reason, the various reporting, oversight, and project closeout activities at the local, state, and federal levels also constitute buyout transaction costs. Indeed, the first costs that are not buyout transaction costs do not occur on average, according to Weber and Moore (2019), until between three and four years after the precipitating flood event, and result from conducting property appraisals (general transaction cost), buying and selling the property (general transaction cost), and demolishing any structures on the property (production cost). Although not enumerated in Fig. 2, this phase also frequently entails environmental assessments - e.g., for asbestos - and remediation, as well as historical preservation reviews. These activities constitute general transaction costs because each would likely be necessary even if there were no federal funding requirements; in order to demolish any structures, historical and environmental reviews and remediation would likely be required by local, state, or federal law, while appraisal and the actual sale of the property are processes familiar to anyone who has ever purchased property. However, because implementing governments have to arrange for contracts with external firms to conduct these tasks (appraisals, environmental reviews, demolition), for example, by putting these tasks out to bid, there are also buyout transaction costs incurred at this stage of a project.

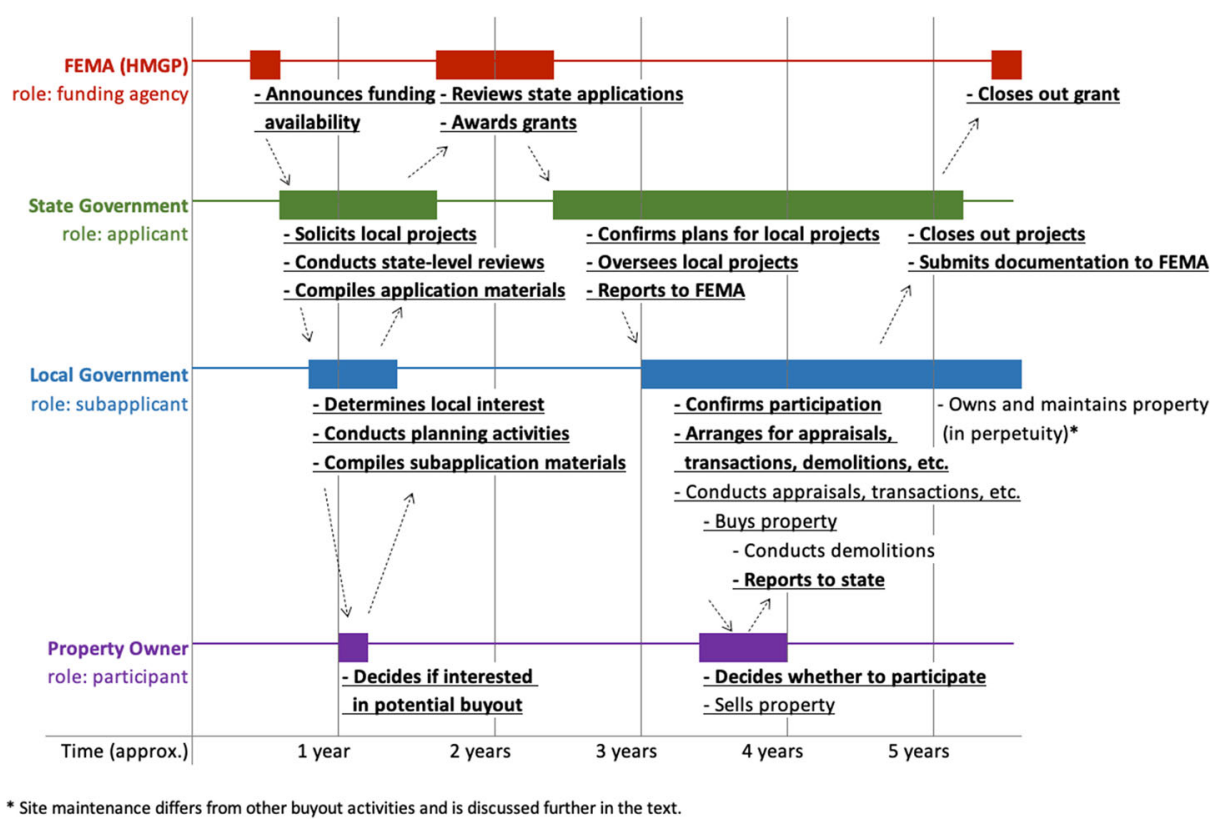

Fig. 2 Timeline of a typical HMGP-funded buyout, with buyout transaction costs bolded and underlined, general transaction costs underlined, and production costs in plain text. Reprinted and adapted with permission from Weber and Moore (2019) 
Lastly, site maintenance differs from other activities listed in Fig. 2 in that it is not a requisite part of a buyout project, but rather a function of post-buyout land use as determined by the local government (Zavar and Hagelman 2016). For example, a local government might devote no resources to site maintenance, might develop and maintain a site as a public park, or might have volunteers maintain the property. As such, we omit site maintenance from our classification of buyout activity costs, though in subsequent sections of the paper we include reports of site maintenance costs in order to develop a more comprehensive understanding of all buyout-related costs.

\subsection{FEMA administrative records}

One potential source of information on buyout costs comes from FEMA, which publishes a number of datasets containing administrative records pertaining to funded hazard mitigation projects. Two of these datasets - one with property-level information (FEMA 2021b), and another with project-level information (FEMA 2021c) - provide relevant cost data for all FEMA-funded hazard mitigation projects dating back to 1990 . We joined these datasets, removed projects that were not related to floodplain buyouts, and summed property-level "Actual Amount Paid" costs to the project level. "Actual Amount Paid" values are proxies for property purchase costs, which are not reported by FEMA; we discuss challenges with this variable below.

Across the 1037 floodplain buyout projects included in these datasets, which in turn account for 5586 acquired properties, the median and mean percentage of project costs spent on "Actual Amount Paid" activities were $84 \%$ and $332 \%$, respectively (SD: 450\%; IQR: 74$94 \%)$. Approximately $16 \%$ of projects $(n=170)$ spent two-thirds or less of their funds on "Actual Amount Paid" activities (see Fig. 3).

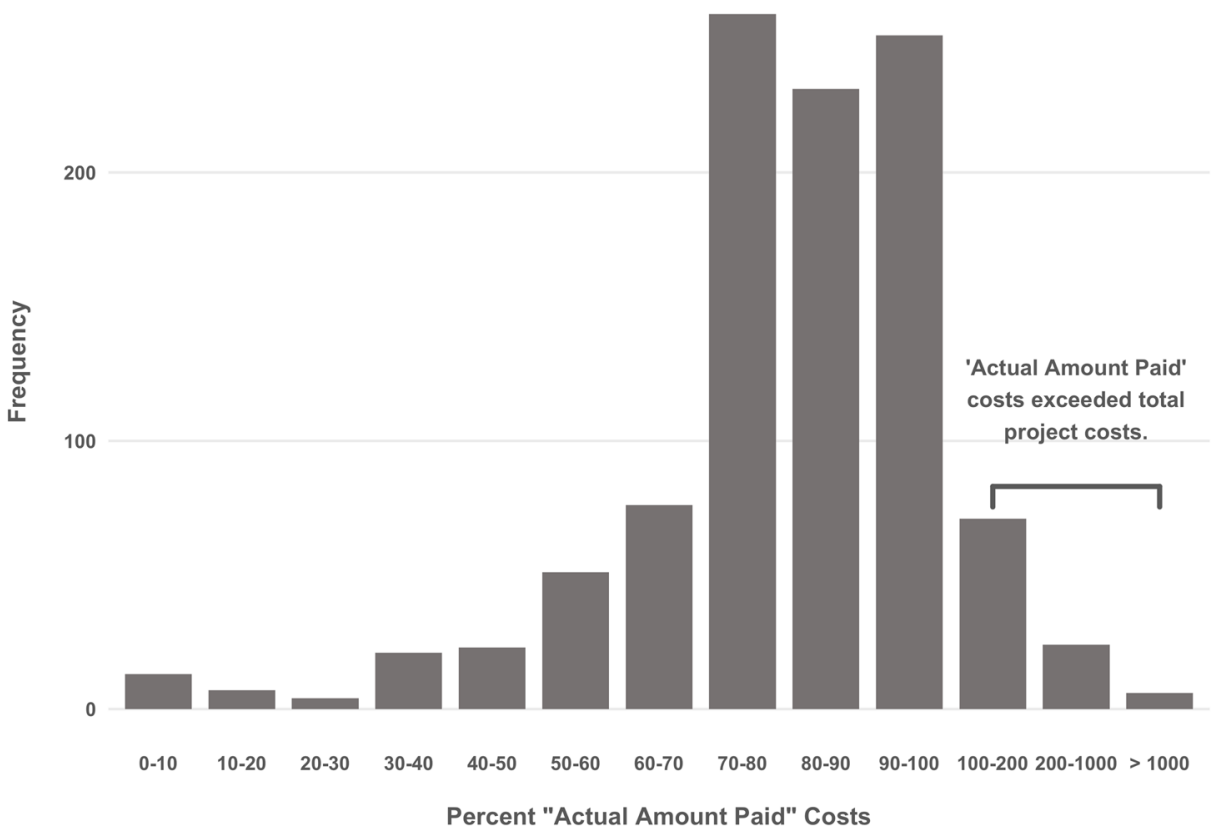

Fig. 3 Percent of total project costs $(n=1037$ projects $)$ represented by "Actual Amount Paid" costs 
As evidenced above and shown in Fig. 3, there are significant issues with data quality that leave us hesitant to draw any conclusions from these results. For example, FEMA inconsistently calculates its "Actual Amount Paid" variable, which does not necessarily equal the market value of the property: this value reflects an unknown combination of the amount paid to the property owner by FEMA, previous disaster aid received, and related costs, such as those for appraisals, closing, and demolition. In addition, many projects $(n=101 ; 10 \%)$ had "Actual Amount Paid" values that exceeded their total project costs; these projects are shown in Fig. 3 as having percent "Actual Amount Paid" costs greater than $100 \%$. While we cannot explain these values, this likely points to poor data quality control or incomplete reporting. These data are also limited in that they do not capture costs incurred at the federal level, nor those incurred by individual homeowners, e.g., the time spent determining one's eligibility or completing program paperwork. They also do not allow us to break down broad cost categories into more relevant activity-level costs.

\section{Methods and data}

We take a two-pronged approach to address our research questions. First, we conduct a systematic review of the peer-reviewed and gray literatures, and second, we analyze the budgets of a sample of communities, counties, and states that have conducted FEMAfunded buyouts.

\subsection{Systematic review}

To investigate the extent to which buyout transaction costs are documented in the literature, we searched relevant publications using the Google Scholar citation search engine. Prior work has found that Google Scholar provides similar coverage of peer-reviewed articles compared to databases such as PubMed, though it may be less specific with the articles included in search results (Anders and Evans 2010; Freeman et al. 2009). Google Scholar aims to index scholarly publications-e.g., "journal papers, conference papers, technical reports, or their drafts, dissertations, pre-prints, post-prints, or abstracts" (Google Scholar 2021) — and thus, we did not systematically review lay sources, such as newspaper articles or op-eds, though some such sources were included in our result set as a function of Google Scholar's indexing algorithm.

We developed suitable search terms by testing different combinations of keywords and Boolean operators and informally evaluating the quality of results. We then corrected for problematic observed factors, such as significant numbers of false positives (e.g., "corporate buyouts"). We also consulted with colleagues involved in a related literature review of floodinduced managed retreat, and ultimately arrived at the search string:

("flood" OR "floodplain")

AND

("buyout" OR "property acquisition" OR "land acquisition" OR "home acquisition"

OR "house acquisition")

AND

(“cost" OR "process" OR "activities" OR "evaluation" OR “analysis").

We used the bibliometric software Publish or Perish (Harzing 2020) to obtain our list of references. Publish or Perish provides an interface for "scraping" the results of literature database searches so as to reduce the manual labor required to individually translate results into 
a workable format for analysis. Using this platform, we examined the metadata for the first 1000 results returned by Google Scholar for our search string. We also solicited additional, relevant documents for review from a network of scholars in this area and incorporated the resulting 103 publications.

After identifying and removing duplicates, we employed a three-tier screening process for evaluating each result: title review, abstract review, and full document review (Fig. 4). For inclusion, we required that results be written in the English language and provide data on the monetary or person-hour costs of floodplain buyouts conducted in the USA. Results were excluded if they did not provide information about floodplain buyouts; if they only presented grant award data; if they did not provide standardized cost estimates (e.g., provided total property purchase prices but did not specify the number of properties or the area of land purchased); or if they were prospective (e.g., modeling costs, benefits, or damages). Results that referenced staff work but did not specify the amount of time dedicated to an activity were also excluded.

ROSES Flow Diagram for Systematic Maps. Version 1.0

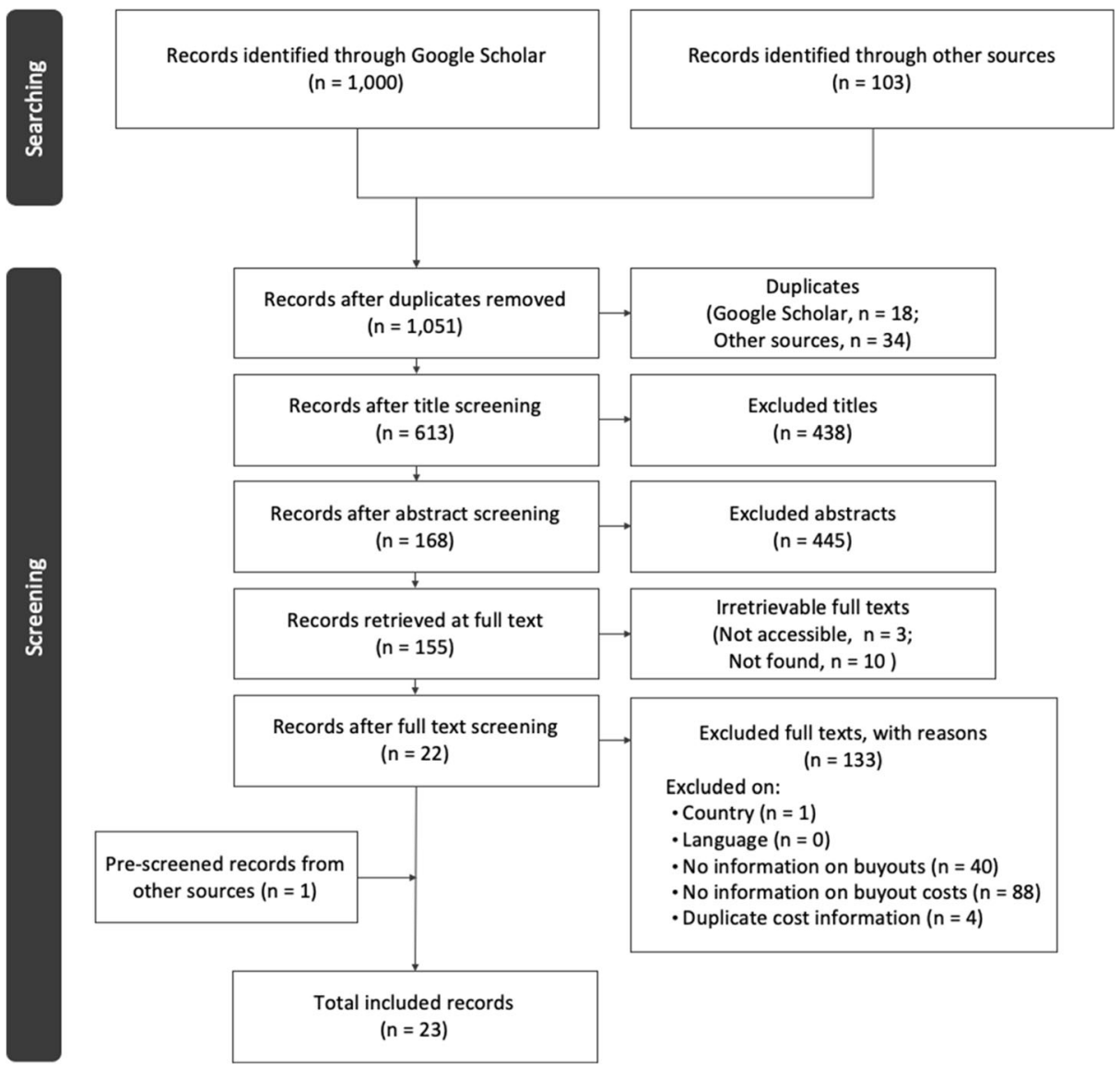

Fig. 4 Record selection process for systematic review of buyout cost literature. Source: adapted from ROSES flow diagram by Haddaway et al. (2017) 
We were unable to obtain 13 of the 1103 records that we identified for review; ten were citations - publications that Google Scholar indexed by crawling reference lists of other records - that were not available online nor through institutional library services or WorldCat (OCLC 2020). The other three unobtainable records were listed on WorldCat but were unavailable due to COVID-19 limitations on library operations. Four full-text records were excluded because they only contained duplicate cost information, either because their entire contribution consisted of citing other included documents or because they presented the same results in different publication formats.

\subsection{Budget review}

The second aspect of this project involved a budget analysis to determine how municipal, county, and state governments track and categorize their own spending on FEMA-funded buyouts. We relied on FEMA's public dataset of hazard mitigation projects (FEMA 2020b) to construct our sampling frame of municipalities for inclusion in this analysis. We retained only those municipalities that were denoted as having initiated riverine or coastal "acquisition/ demolition" projects (i.e., containing "type" codes 200.1-200.4). Several trial efforts to review municipal budgets revealed a steep drop-off of available information after five years (prior to 2015). Therefore, we limited our investigation to municipalities where buyouts were approved on or after January 1, 2015.

We used a random stratified sampling approach to over-sample municipalities that had acquired relatively large numbers of properties through floodplain buyouts, based on our hypothesis that these places were more likely to have relevant information in their budgets. We sampled every municipality with more than 50 properties acquired between 2015 and 2020 ( $n$ $=48$ municipalities) and randomly sampled $5 \%$ of the remaining municipalities with 50 or fewer properties acquired over the same time period ( $n=50$ municipalities). For each sampled municipality, we also included in our sample the encompassing county and state, since multiple levels of government are often involved in administering buyout funding and activities. Because counties are often responsible for buyout implementation when major flooding occurs outside of larger, incorporated areas, we also sampled those counties where more than 100 properties had been acquired, which generated two additional observations (Kanawha County, WV and Brazoria County, TX; most such counties had already been included). Our resulting sample, shown in Fig. 5, comprised 98 unique municipalities, 81 unique counties, and 25 unique states. However, after accounting for places where no budgetyears were available, our effective sample comprised 67 unique municipalities, 62 unique counties, and 25 unique states.

For each municipality sampled, we implemented an online search for budget documentation from the fiscal year(s) during which the municipality was initially approved for funding, as well as the years directly after the approved buyout (until the earlier of either 2020 or the year in which the buyout project was officially closed out) to account for possible time lags in project implementation. We used this same process to identify budgets for encompassing counties and states. This generated a total sample of 859 budget-years. Of these budget-years, $223(26 \%)$ were not available online, and an additional $76(9 \%)$ were not machine readable (resulting in an effective sample size of $n=560$ budget-years).

To identify potentially relevant text in the budgets, we searched each document for the following keywords: "flood," "buyout," "FEMA," "hazard," "mitigation," and "acquisition." We then coded budgets iteratively, seeking a limited number of categories that were common 


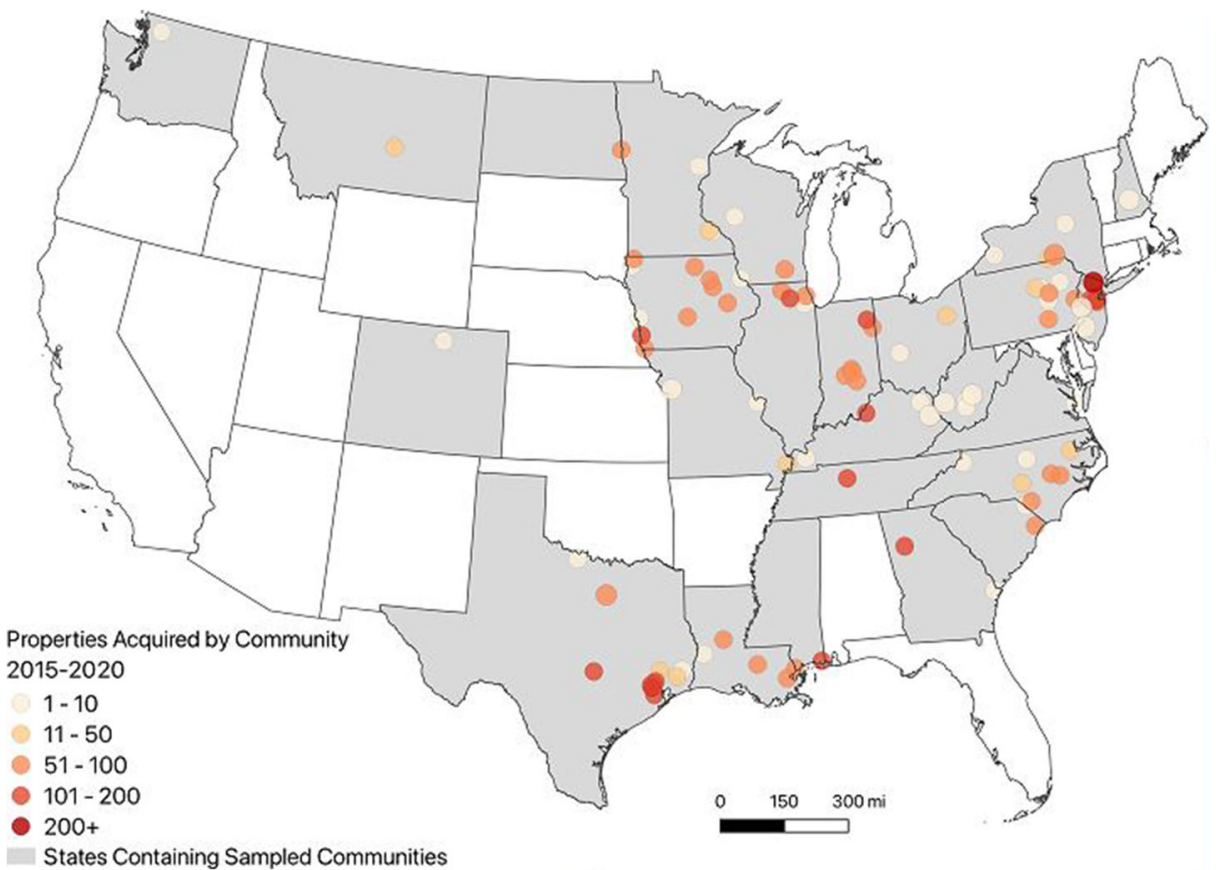

Fig. 5 Municipalities sampled for budget review $(n=98)$ by number of FEMA-funded properties acquired from 2015 to 2020. Note: While all states and US territories were included in the sample frame, only the 48 conterminous states are mapped here to better represent those municipalities that were sampled

across budgets and contained information relevant to buyout costs; we settled on "flood mitigation," "property acquisitions," and "flood buyouts." We documented flood mitigation and property acquisitions because budgets at times provided cost data on these broader budget categories instead of or in addition to information on the costs of floodplain buyouts. As our focus was the activity costs of buyout projects, only explicit expenditures were coded as present; if a budget discussed flood mitigation projects, for example, but did not provide cost data, that budget was coded as not containing relevant flood mitigation data. When a budget itemized floodplain buyout costs, we recorded total buyout expenditures, the full-time equivalent staff dedicated to buyouts, and resource allocations for the buyout activities identified in Weber and Moore (2019).

\section{Results}

\subsection{Systematic review}

We identified very few published documents $(n=23 ; 2 \%$ of reviewed documents) that itemized the costs, either in terms of expenditures or person-hours, of specific activities comprising floodplain buyouts; these documents are described in Appendix Table 1. Of the 23 included documents, the large majority $(n=19 ; 83 \%)$ specified only property purchase prices, while three documents $(13 \%)$ provided information on property purchase prices and another activity, and one document (4\%) only described asbestos testing costs. Other itemized 
activity costs included site maintenance (4\%); property purchase price and relocation costs (reported jointly; 4\%); appraisal, property purchase price, and demolition (reported jointly; 4\%); and asbestos testing (4\%; see Fig. 6A).

While costs identified in the literature aligned with a subset of the activities described by Weber and Moore (2019); see Fig. 1), there was no cost information for many activitiesespecially those relating to the administrative and communicative aspects of a buyout, such as the staff time required to inform residents about a buyout opportunity or to conduct benefitcost analyses. There was also no cost information for activities undertaken by state and federal government agencies, nor for the costs incurred by individual participants (e.g., learning about

A

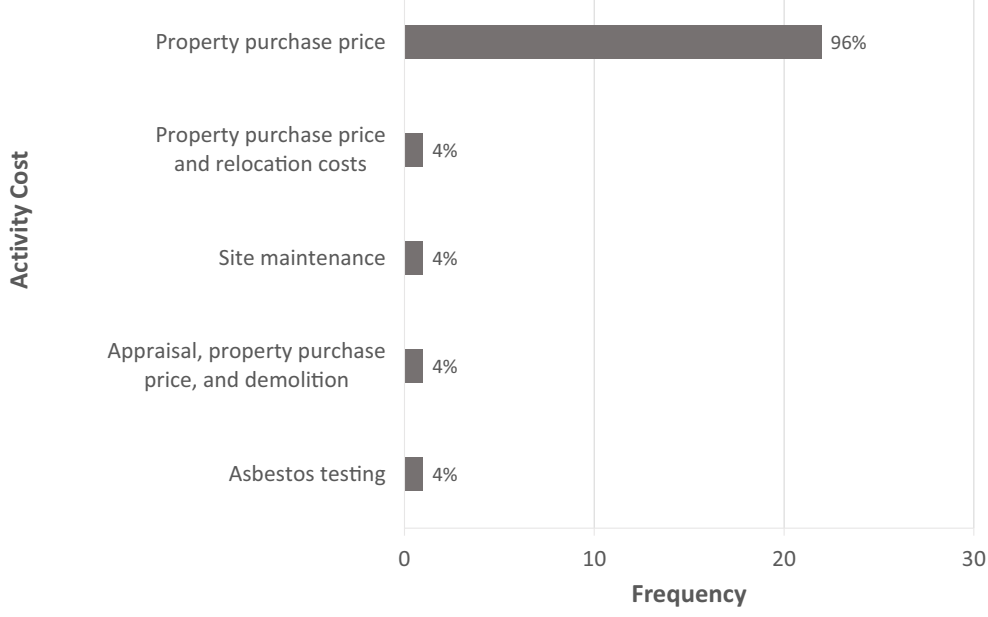

B

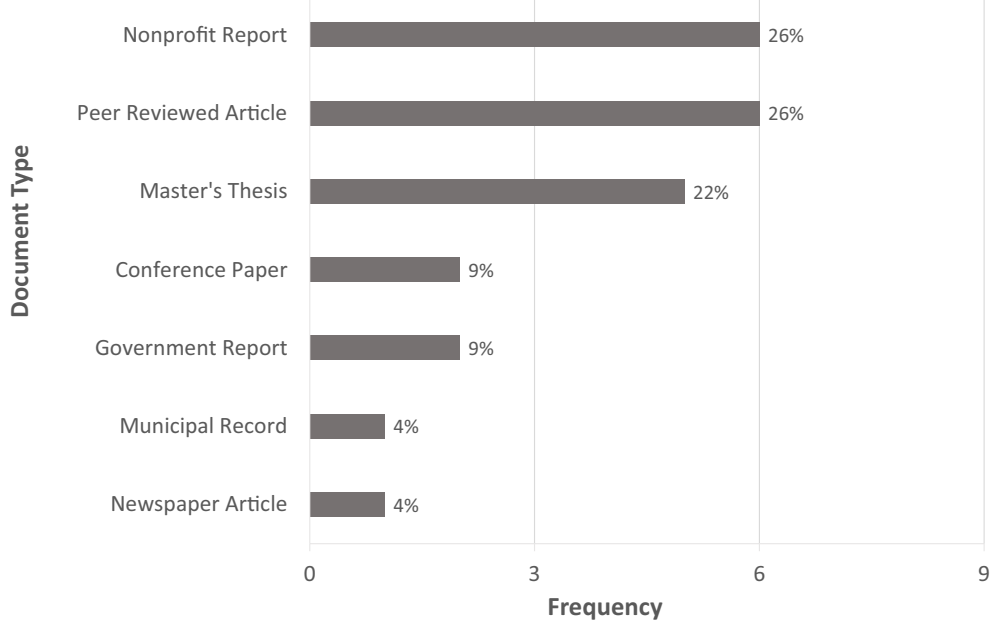

Fig. 6 A Frequency (with percentage of total) of itemized activity costs among documents that included any cost information (total $n=23$ ). Note: Counts and percentages do not sum to total because some documents itemized costs associated with multiple activities. B Frequency (with percentage of total) of analyzed documents, by publication type (total $n=23$ ) 
the buyout project and their eligibility; hiring legal support). Furthermore, the cost information reported in most of the included documents was project specific-i.e., did not aggregate activity costs across projects - thus limiting the generalizability of findings. An important exception were the site maintenance costs reported in BenDor et al. (2020), which reflected a synthesis of data from multiple municipalities' buyout projects.

Included documents were published over a significant timespan, from 1987 through 2020, and by a range of entities, including both academic and non-academic sources (Fig. 6B). While a quarter $(n=6 ; 26 \%)$ of documents were peer-reviewed journal articles, two-thirds $(n=16$; $74 \%$ ) were from the gray literature (e.g., government reports) or from lay sources (newspaper articles $[n=1]$ and municipal records $[n=1])$. Google Scholar does not intend to index nonscholarly documents (Google Scholar 2021), which may explain the relative infrequency of these sources in our results. Notably, a municipal record - specifically, a city council meeting addendum - was the only document we identified that did not itemize property purchase prices, and was also the only document that specified asbestos testing costs (City of Waverly 2015).

In 10 cases $(43 \%)$, we were unable to disambiguate whether reported costs referred to overarching project costs or specifically to property purchase costs. For example, Plastrik and Cleveland (2019, p. 22) wrote that "[The Charlotte-Mecklenburg stormwater utility] has spent $\$ 68$ million to buy and demolish 400 buildings on its floodplain." Freudenberg et al. (2016, p. 54) used similar language to describe the costs of a buyout program: " $\$ 48.4$ million was awarded for the purchase and demolition of 196 homes in Sayreville [NJ] and \$15.2 million was awarded for the purchase and demolition of 76 homes in neighboring South River." These descriptions of buyout costs are ambiguous for multiple reasons. For one, FEMA refers to buyouts as "acquisition/demolition" projects, which may contribute to the usage of "buy and demolish," "purchase and demolition," and similar terms as substitutes when referring to the myriad activities comprising a buyout. Furthermore, grant awards cover more than just the discrete costs associated with acquisition and demolition, such as staff costs for program implementation, suggesting that such phrasing may refer to total project funding as opposed to merely property purchase prices and demolition costs. Documents with ambiguous language are noted in Appendix Table 1 with an asterisk.

\subsection{Budget review}

Overall, states over counties, and counties over municipalities, were more likely to have a website, to have a publicly accessible budget, and to explicitly report information on flood mitigation, property acquisitions, and flood buyout expenditures. Of the budget-years comprising our effective sample $(n=560), 55 \%(n=310)$ itemized flood mitigation expenditures, $36 \%(n=204)$ itemized property acquisition (in a flooding context) expenditures, and $5 \%(n$ = 29) itemized floodplain buyout costs (see Fig. 7). None of the budgets that provided buyout cost information provided information on FTEs dedicated to buyouts or on how costs were broken down across the activities described by Weber and Moore (2019; Fig. 1).

Despite drawing our sample from budget-years in which we knew HMGP buyout grants were active, only a small proportion of budgets itemized buyout costs. Of those that did, many described their buyout activities with only a single line item in the budget; Manville's (New Jersey) 2018 budget (Borough of Manville 2019, p. 48) is characteristic of this, with a single line-item, for $\$ 437,474$, titled "Acquisition and Demolition of Flood Damaged Properties." Manville's budget also lists a number of other revenues and expenses that might relate to 


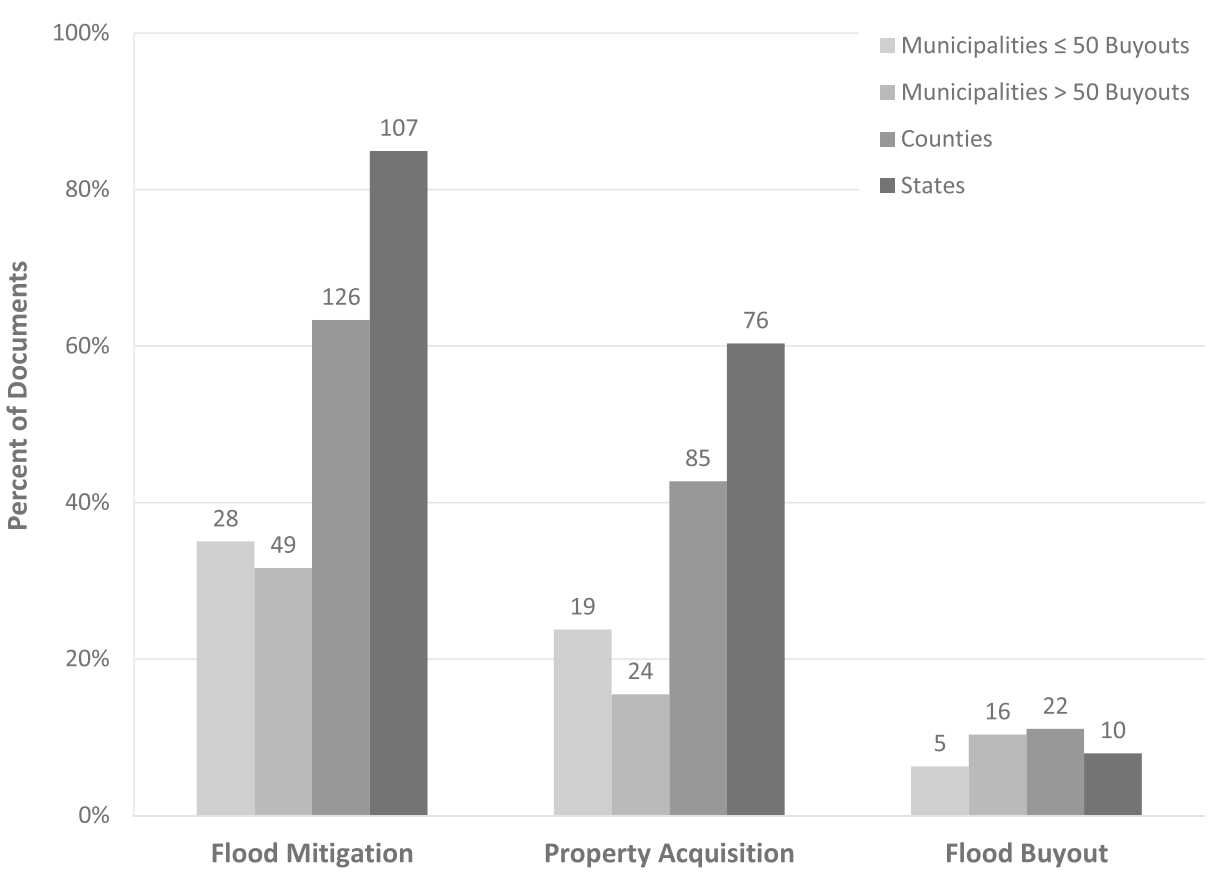

Fig. 7 Percentage (and frequency) of study municipalities (categorized based on number of properties acquired from 2015 to 2020), counties, and states with budget information on flood mitigation, property acquisitions, and flood buyouts

floodplain buyouts, e.g., a FEMA grant for \$1,070,010 labeled "FEMA - 2018 Flood Mitigation," and a corresponding county matching grant for $\$ 118,890$ labeled "FEMA 2018 Flood Mitigation - County Match" (p. 17). However, because FEMA-funded flood mitigation can encompass many non-buyout projects, such as elevations, these latter line items contribute little to our understanding of buyout costs. Indeed, even the more specific buyout costs itemized in Manville's budget add little to our understanding of buyout costs because they provide no activity-level cost details.

The City of Mason City's (Iowa) 2015 budget provided perhaps the greatest level of detail regarding buyout costs among the budgets we reviewed, both through narrative descriptions of buyout activities and through tabulations of revenues and expenditures relating to buyout projects. Of note, Mason City appears to have two standing funds that it uses to coordinate, at least in part, buyout activities: an "HMGP Voluntary Acquisition Special Revenue Fund" and an "FMA ${ }^{3}$ Voluntary Acquisition Special Revenue Fund (pgs. 93-94)." While this budgeting approach included relatively detailed buyout expenditures - "Personal Service," "Contractual," and "Commodities" costs are all itemized - this breakdown does not meaningfully align with the functional components of a buyout project, but rather is a typology that Mason City uses to document expenditures across a range of funds and activities. Mason City's narrative

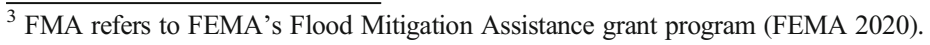


describes completed and future-facing buyout activities in some detail: "The buyout and demolition efforts related to the June 8, 2008 flood event in the community are essentially complete, although a small area of an additional nine homes has been identified for a floodrelated buyout. A Buyout Administrator coordinates this effort. A total of 169 houses were purchased and either demolished or moved due to the 2008 flood; the land will become permanent public open space (pg. 7)." While it is notable that Mason City has a role dedicated to coordinating its buyouts, this narrative text ultimately provides no information about activity-level buyout costs.

Because information specific to floodplain buyouts was limited, we also coded documents for expenditures relating to flood mitigation activities and property acquisitions that might constitute floodplain buyouts. These expenditures were potentially relevant to buyout costs for two reasons: they might encompass buyout costs, albeit without specifically denoting them; and they provide useful comparisons for evaluating whether the level of detail afforded buyouts in budgets was typical, or whether places tended to provide less information about buyout expenditures than they did for other similar classes of expenditures.

Ultimately, the details provided for flood mitigation and property acquisition expenses were no more specific nor insightful than those provided for floodplain buyouts. Austin's (TX) 2016 budget (City of Austin 2017) provides a representative example in its discussion of the Waller Creek Tunnel, which it describes as a project designed "to address problems of flooding, erosion, and water pollution along [the] lower Waller Creek (pg. 6)." The budget narrative refers to municipal bonds, a portion of which $-\$ 11,051,000$ - were dedicated to the project for fiscal year 2016 (p. 72), and an accounting of Capital Projects Funds (p. 164) notes the tunnel project has total assets of $\$ 8,249,000$. Yet, akin to the buyout projects described above, there are no additional details that describe how costs are incurred (e.g., for labor, materials, land acquisition).

\section{Discussion and conclusions}

Neither the data that FEMA publishes, the scholarly literature, nor governments' annual budgets provide reliable information about activity-level buyout costs. After reviewing over 1100 scholarly documents relating to floodplain buyout costs, we identified only 23 published documents that provided activity-level cost information. Of a sample of 560 budget-years, we did not find a single budget that itemized activity-level costs, though $9 \%(n=53)$ explicitly listed the cost of overarching buyout projects, and a number of others discussed buyout projects without providing cost information. The information available often presents only a partial picture of the total costs, in that only property purchase prices or specific grant awards are reported.

Our results, or the lack thereof, are particularly concerning in light of widespread evidence that buyout projects do involve extensive transaction costs, including communicating with potential buyout participants (Binder and Greer 2016; Martin et al. 2019), conducting benefitcost analyses (FEMA 2015a; US GAO 2021) and environmental hazard reviews (FEMA 2015b), and completing administrative reporting requirements (Weber and Moore 2019; Martin et al. 2019). The lack of documentation may result because many local governments only sporadically engage in buyouts; if local officials have never implemented a buyout project before and do not expect to repeat the process in the future, there is little reason to capture any of the time or activity-level costs. There are also no requirements or incentives to do so by state 
or federal agencies - nor even guidance and tools to support such accounting - and logging hours and costs may be tedious. The result is that, in both budgets and the scholarly literature, grant awards and property purchase prices are widely reported, while other, less tangible project costs are not even mentioned. Yet, property purchase price information provides little basis for future projects to learn from and improve on past experience.

Incomplete reporting of buyout costs and the focus on property purchase costs also mask the potentially significant staff time across the many agencies and levels of government involved in a typical buyout project, both because state and local staff may informally dedicate their time to buyout activities, and because grant awards do not capture the costs of buyout projects incurred at the federal level. It also ignores the costs imposed on prospective project participants, who have to invest time to learn about the opportunity, complete paperwork, and wait - oftentimes for years - to receive a buyout offer. These buyout transaction costs may have implications for the equity of existing buyout structures: for example, prospective participants with fewer resources or less formal education may have to expend more time and money to navigate buyout processes than their counterparts and may be more likely to find these processes prohibitive to actually participating in a buyout.

The near total absence of any activity-level cost information is also highly problematic for efforts to learn from and improve buyout policy. Some activities, such as designing the buyout project along with the community and communicating frequently with property owners, are crucial to the outcomes of buyout projects. These activities should be supported to encourage more transparent and equitable buyout projects (Siders 2018). By contrast, other non-purchase activities may create delays without contributing significantly to enhancing participant and program outcomes. Without activity-level data, it is impossible to identify where transaction costs can be eliminated and where additional funding may be needed. Activity cost data could support other aspects of program reform as well: for example, data from a range of projects would enable evaluators to examine whether there are economies of scale for projects acquiring many properties, which might in turn inform efforts to consolidate buyout project implementation at the county level when properties are scattered across multiple municipalities.

The lack of systematic cost information to date and the challenges associated with aggregating such information from alternate sources, such as departmental budgets and grant awards, also point to the need for better financial data collection standards by FEMA and HUD. A simple budgeting tool that aligns with the activities identified in Fig. 2 could be integrated into existing project reporting processes for both FEMA- and HUD-funded buyouts. Over time, such data would allow for comparison of buyouts across funding mechanisms, support transaction cost evaluations of projects, and enable governments prospectively considering buyouts to better plan and budget for their estimated expenses. Until reporting standardizes and aggregates these data, future research might seek to systematically quantify the costs of the various activities that comprise typical floodplain buyout projects, for example, through primary data collection from individuals engaged in funding and implementing buyouts.

Adjustments to program design could also affect the reach of existing buyout programs. Substantial transaction costs may be preventing local governments with less capacity from engaging in buyout programs at all (Mach et al. 2019), and reducing those barriers could open up access to a broader population. Several jurisdictions have already instituted independently 
funded buyout programs to increase their own flexibility. For example, New Jersey's stateoperated Blue Acres program blends funding from HMGP, CDBG, state legislative appropriations, and the US Department of Agriculture's Natural Resources Conservation Service to conduct buyouts more quickly and strategically than is typical (Weber 2019a; NJ Department of Environmental Protection 2015). Charlotte-Mecklenburg (NC) Stormwater Services (SWS) operates a locally funded buyout program that acquires properties within its joint city-county jurisdiction in roughly six months after flooding. The program was developed in response to the length of FEMA-funded buyouts, which led to higher program attrition and costs, as buyout offers would have to pay for repairs and updates made in the intervening years after the precipitating flood event. Notably, Charlotte-Mecklenburg's approach identifies potential buyout properties before the flood so that SWS can execute acquisitions more quickly when flooding does occur (Weber 2019b).

Although we collected and analyzed data from multiple sources in an effort to assess activity-level buyout costs, our approach had a number of limitations. First, while our budget analysis examined a broad set of municipal, county, and state budgets, we did not examine the budgets of other entities involved in administering floodplain buyouts, such as flood control districts. We focused on jurisdictions' annual budgets because these are almost universally required, although some jurisdictions' budgets $(26 \%)$ were nonetheless unavailable online. Future research might evaluate finer grained sources of financial data, such as grant awards, government contracting records, or the budgets of more specialized units, e.g., flood control districts or individual government departments. However, these sources are much less likely to be universally available than were annual government budgets, limiting the generalizability of any results. Second, given that federal funding streams uniquely shape how buyout projects are implemented in the USA, we did not examine literature or other data sources relating to buyouts conducted in other countries. While our results may be relevant to other countries' work to design and implement more efficient and equitable buyout programs, efforts to reform US buyout programs might also benefit from an extension of this transaction cost analysis to buyout projects conducted internationally. Lastly, the sample for our budget analysis was drawn from FEMA records and thus did not necessarily include budget-years for jurisdictions that implemented buyouts without any FEMA funding. This was in part intentional, given that our primary focus in this paper was the application of activity cost data to reforming federally funded buyouts. However, activity cost data from buyouts funded without federal assistance may be valuable in helping to characterize and learn from alternate approaches to implementing buyouts.

In summary, a more nuanced understanding of costs in relation to structural aspects of buyout projects may highlight existing best practices and help to promote policy learning, which has been limited to date (Greer and Binder 2017). By assessing buyout activity costs within a transaction cost framework, policymakers and program staff may identify and test alternate program requirements and project structures, with an eye toward minimizing staff burden and costs associated with activities that produce few benefits. These improvements will help property owners relocate more speedily, and cost savings and other efficiency gains will mean more resources can be devoted to core buyout activities that maximize participants' well-being and promote more equitable outcomes. Such efforts are urgently needed given the potential increase in demand for buyouts as the climate changes and flood damages grow. 


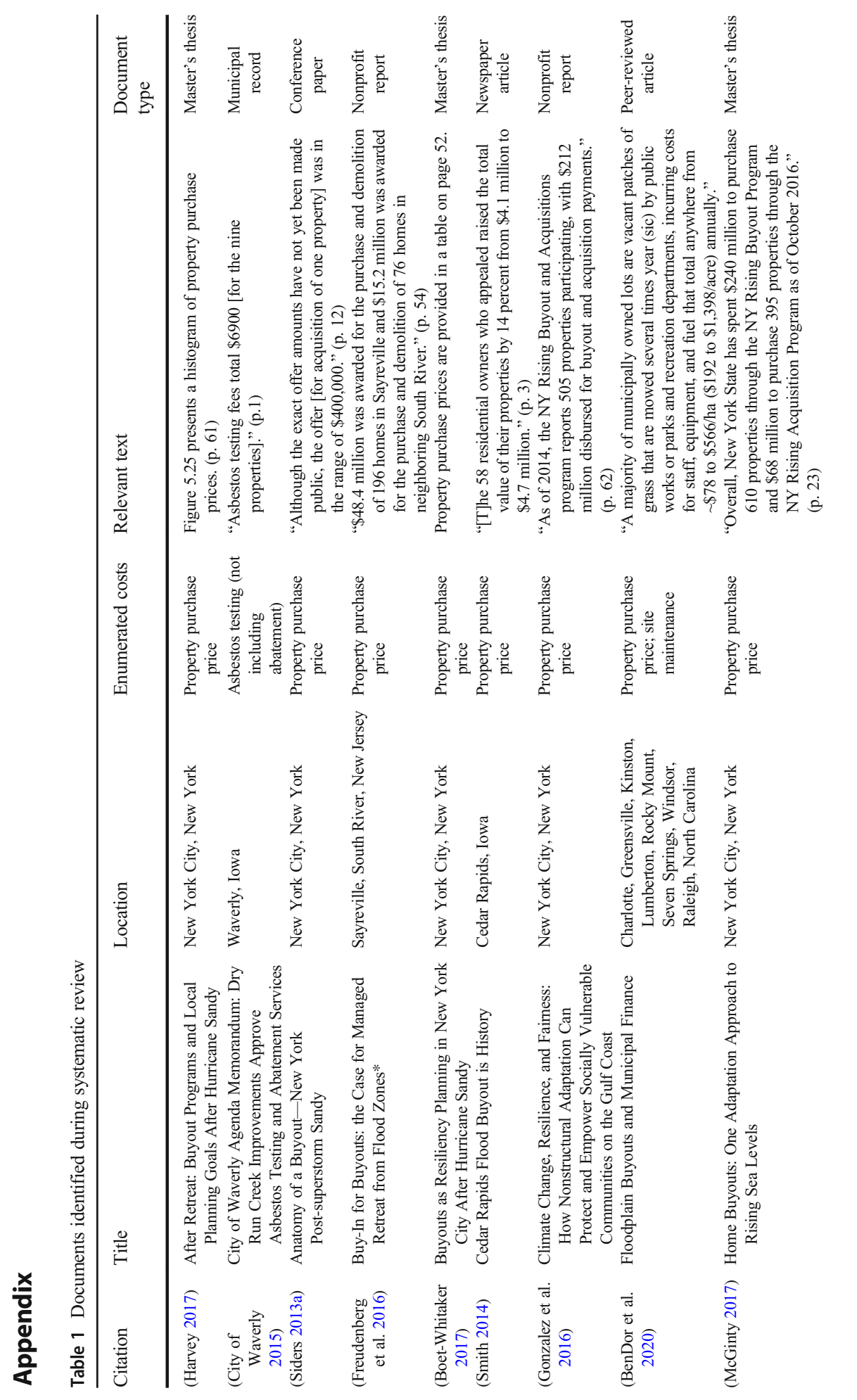




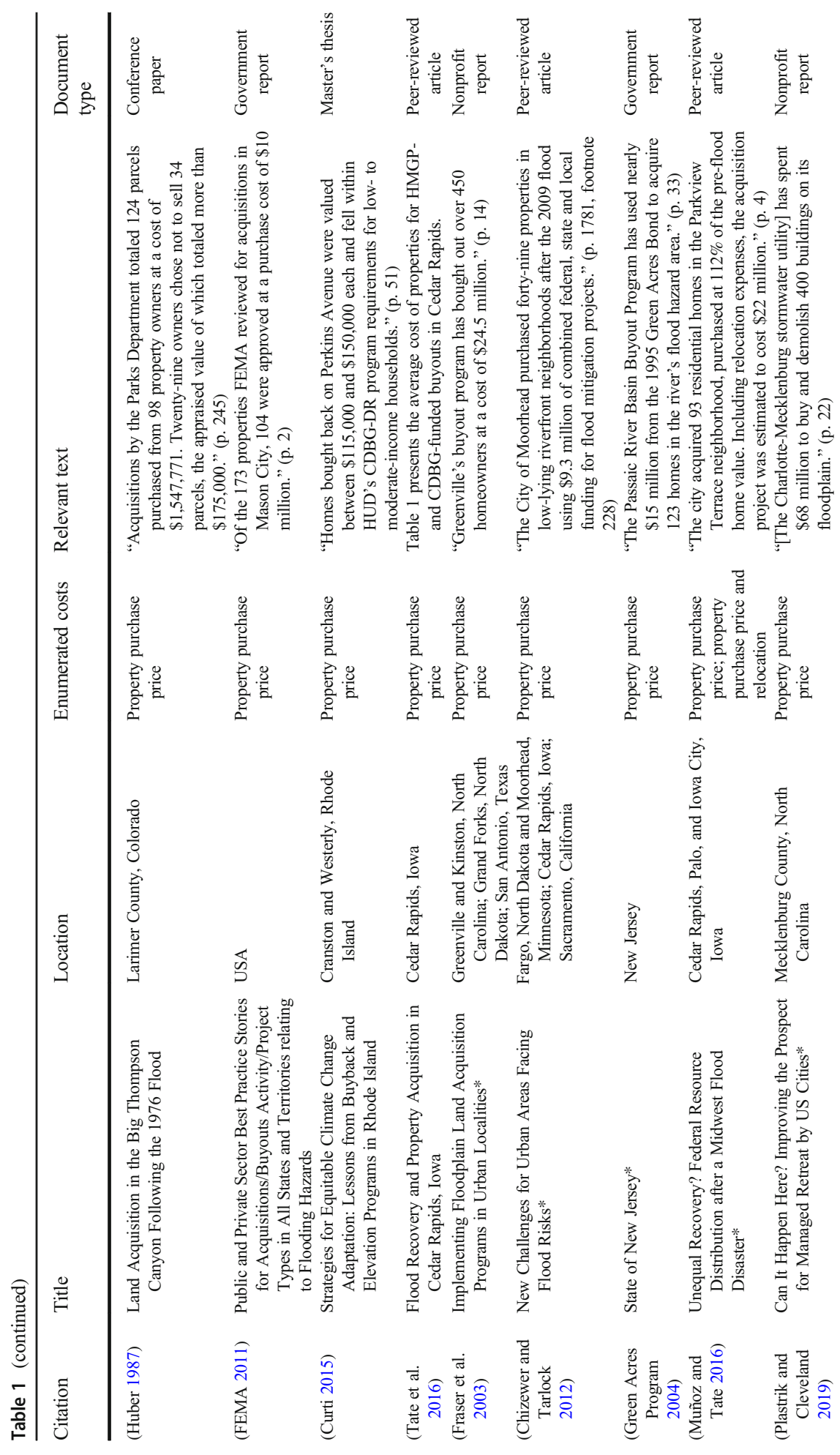




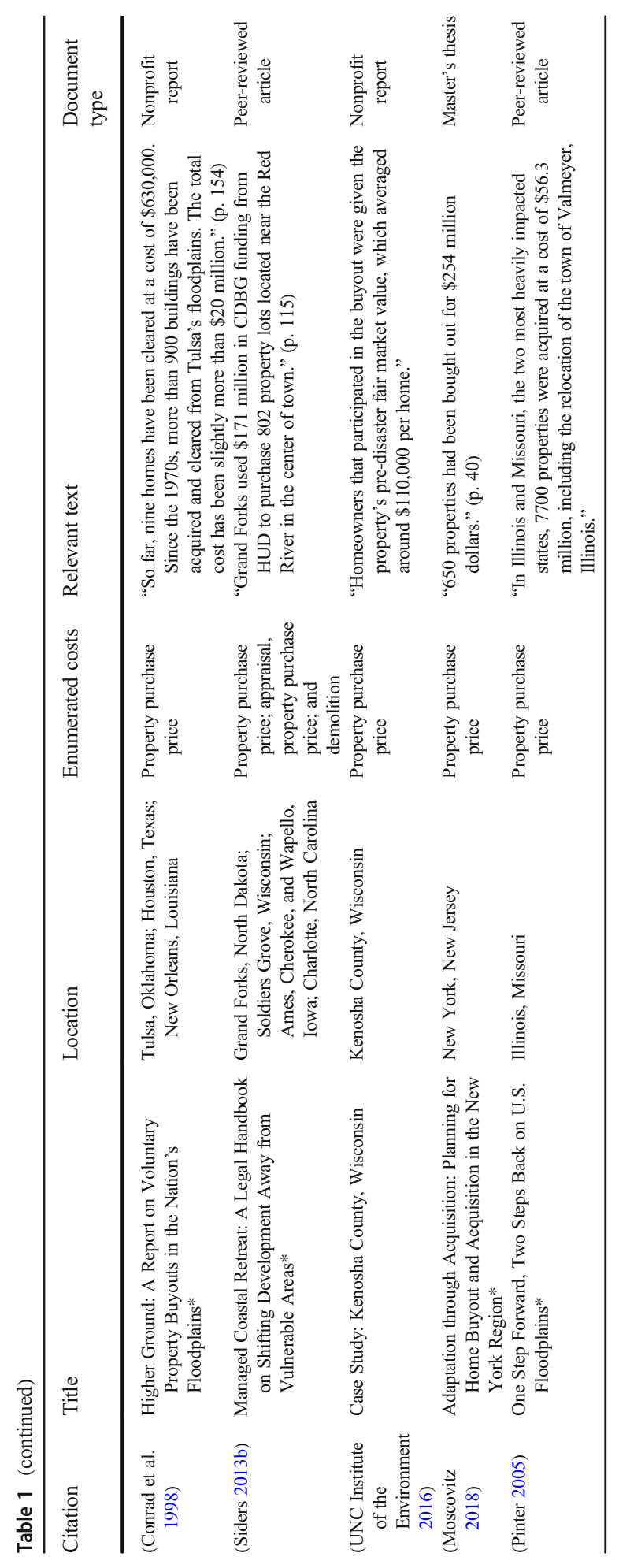

\section{글 Springer}


Availability of data and material Data is available via UNC dataverse: Curran-Groome, William, Hallee Haygood, Miyuki Hino, Todd K. BenDor, and David Salvesen. Assessing the Full Costs of Floodplain Buyouts. 2021. "Replication Data for: Assessing the full costs of floodplain buyouts", https://doi.org/10.15139/S3/ IARBJE, UNC Dataverse.

Code availability Code is available via UNC dataverse: Curran-Groome, William, Hallee Haygood, Miyuki Hino, Todd K. BenDor, and David Salvesen. Assessing the Full Costs of Floodplain Buyouts. 2021. "Replication Data for: Assessing the full costs of floodplain buyouts", https://doi.org/10.15139/S3/IARBJE, UNC Dataverse.

Author contribution W.C.-G. led the manuscript writing and literature review; H.H led the budget review and assisted in writing the manuscript; M.H. assisted in writing and editing the manuscript; T.K.B. and D.S. assisted in writing and editing the manuscript and gained project funding.

Funding This paper is based on work supported by the North Carolina Policy Collaboratory and through the US National Science Foundation under Coastal SEES Grant No. 1427188 and Geography and Spatial Sciences Grant No. 1660450. We would also like to thank Chris Crew (NC Division of Emergency Management).

\section{Declarations}

Ethics approval Not applicable

Consent to participate Not applicable

Consent for publication Not applicable

Conflict of interest The authors declare no competing interests.

\section{References}

Anders ME, Evans DP (2010) Comparison of PubMed and Google Scholar literature searches. Respir Care 55(5):578-583

Baker CK., Binder SB, Greer A, Weir P, Gates K (2018) Integrating community concerns and recommendations into home buyout and relocation policy. Risk, Hazards \& Crisis in Public Policy 9(4):455-479.

BenDor TK, Salvesen D, Kamrath C, Ganser B (2020) Floodplain buyouts and municipal finance. Natural Hazards Review

Binder SB, Greer A (2016) The devil is in the details: linking home buyout policy, practice, and experience after hurricane sandy. Politics and Governance 4(4):97

Binder SB, Greer A, Zavar E (2020) Home buyouts: a tool for mitigation or recovery? Disaster Prev Manag

Boet-Whitaker SK 2017. Buyouts as resiliency planning in New York City after Hurricane Sandy. Master thesis

Borough of Manville 2019 Annual financial statement 2019. Borough of Manville

Bryson JM, Ring PS (1990) A transaction-based approach to policy intervention. Policy Sci 23(3):205-229

Buitelaar E (2004) A transaction-cost analysis of the land development process. Urban Stud 41(13):2539-2553

Chizewer DM, Tarlock AD (2012) New challenges for urban areas facing flood risks. Fordham Urb, LJ

City of Mason City (2015) Comprehensive annual financial report 2015. City of Mason City

City of Waverly (2015) Agenda Memorandum: City Council Meeting [Online]. Available at: http://agendas. waverlyia.com/documents/Public/City\%20Council/2015\%20Agenda\%20Manager\%20Attachments/01-0515/res\%2015-04.pdf [Accessed: 1 June 2020]

Conrad DR, Stout M, McNitt B, et al. (1998) Higher ground: a report on voluntary property buyouts in the nation's floodplains: a common ground solution serving people at risk, taxpayers and the environment. National Wildlife Federation

Curti JM (2015) Strategies for equitable climate change adaptation: lessons from buyback and elevation programs in Rhode Island. Master thesis 
Davenport FV, Burke M, Diffenbaugh NS (2021) Contribution of historical precipitation change to US flood damages. Proc Natl Acad Sci U S A 118(4)

Dyckman CS, St. John C, London JB (2014) Realizing managed retreat and innovation in state-level coastal management planning. Ocean Coast Manag 102:212-223

Feiock RC (2001) A transaction cost theory of federalism. Meeting of the Southern Political Science Association

FEMA (2011) Mitigation best practices: public and private sector best practice stories for acquisition/buyouts activity/project types in all states and territories relating to flooding hazards

FEMA (2013) Loss Avoidance Study: Austin, Minnesota, 163 Building Acquisitions [Online]. Available at: http://www.ci.austin.mn.us/Engineering/PDF/Final2013.pdf [Accessed: 1 June 2021]

FEMA (2015a) Hazard Mitigation Assistance Guidance 2015. Available at: https://www.fema.gov/medialibrary/assets/documents/103279 [Accessed: 19 February 2021]

FEMA (2015b) Hazard Mitigation Assistance Guidance Addendum: Hazard Mitigation Grant Program, PreDisaster MitigationProgram, and Flood Mitigation Assistance Program. . Available at: https://www.fema. gov/sites/default/files/2020-07/fy15_hma_addendum.pdf [Accessed: 3 December 2020]

FEMA (2018) 30 Years of Hazard Mitigation Assistance [Online]. Available at: http://30years.unifiedhma.com/ [Accessed: 18 July 2020]

FEMA (2020a) Frequently Asked Questions: Hazard Mitigation Grant Program Management Costs Policy (Interim). . Available at: https://www.fema.gov/sites/default/files/2020-07/hma_management-cost-faq_323-2020.pdf [Accessed: 19 February 2021]

FEMA (2020b) OpenFEMA Dataset: Hazard Mitigation Assistance Projects - V1 [Online]. Available at: https:// www.fema.gov/api/open/v1/HazardMitigationAssistanceProjects [Accessed: 31 May 2020]

FEMA (2021a) Loss Avoidance Study: Birmingham, AL Acquisitions [Online]. Available at: https://www.fema. gov/case-study/loss-avoidance-study-birmingham-al-acquisitions [Accessed: 14 June 2021]

FEMA (2021b) OpenFEMA Dataset: Hazard Mitigation Assistance Mitigated Properties - V2 [Online]. Available at: https://www.fema.gov/openfema-data-page/hazard-mitigation-assistance-mitigated-propertiesv2 [Accessed: 30 January 2021]

FEMA (2021c) OpenFEMA Dataset: Hazard Mitigation Assistance Projects - V2 [Online]. Available at: https:// www.fema.gov/openfema-data-page/hazard-mitigation-assistance-projects-v2 [Accessed: 31 January 2021]

Fraser J, Elmore R, Godschalk D Rohe W (2003) Implementing floodplain land acquisition programs in urban localities. UNC-Chapel Hill Center for Urban \& Regional Studies

Freeman MK, Lauderdale SA, Kendrach MG, Woolley TW (2009) Google Scholar versus PubMed in locating primary literature to answer drug-related questions. Ann Pharmacother 43(3):478-484

Freudenberg R, Calvin E, Tolkoff L Brawley D (2016) Buy-in for buyouts: the case for managed retreat from flood zones. Lincoln Institute of Land Policy

Gonzalez CG, Kaswan A, Verchick R, Huang Y Jamhour N (2016) Climate change, resilience, and fairness: how nonstructural adaptation can protect and empower socially vulnerable communities on the Gulf Coast. Center for Progressive Reform

Google Scholar (2021) Inclusion Guidelines for Webmasters [Online]. Available at: https://scholar.google.com/ intl/en/scholar/inclusion.html\#content [Accessed: 15 June 2021]

Green Acres Program (2004) 2005-2007 Land Preservation Plan. New Jersey Department of Environmental Protection

Greer A, Binder SB (2017) A historical assessment of home buyout policy: are we learning or just failing? Hous Policy Debate 27(3):372-392

Haddaway NR, Macura B, Whaley P Pullin AS (2017) ROSES flow diagram for systematic maps. Version 1.0

Hamel L, Wu B, Brodie M, Sim Sh-C Marks E 2018. One year after the storm: Texas Gulf Coast residents' views and experiences with Hurricane Harvey recovery: the Kaiser Family Foundation/Episcopal Health Foundation Harvey Anniversary Survey. Kaiser Family Foundation / Episcopal Health Foundation

Harvey DC (2017) After retreat: buyout programs and local planning goals after Hurricane Sandy. Master thesis

Harzing AW (2020) Publish or perish. Harzing

Huber C (1987) Land acquisition in the Big Thompson Canyon following the 1976 flood. In: Gruntfest, E. ed. What we have learned since the Big Thompson flood: proceedings of the tenth anniversary conference, July 17-19, 1986, Boulder, Colorado. Natural Hazards Research and Applications Information Center, pp. 245-251

HUD (2013) Disaster Recovery Buyout Program Guidelines [Online]. Available at: https://www.hudexchange. info/resource/2862/disaster-recovery-buyout-program-guidelines/ [Accessed: 30 July 2020]

HUD (2019) Community Development Block Grant Disaster Recovery (CDBG-DR): policy guidance for grantees 2019. HUD Exchange

Kick EL, Fraser JC, Fulkerson GM, McKinney LA, De Vries DH (2011) Repetitive flood victims and acceptance of FEMA mitigation offers: an analysis with community-system policy implications. Disasters 35(3):510 539 
Kummerer S (2019) It's your money: conway plans to buy more than 40 homes to prevent future flooding [Online]. Available at: https:/www.wmbfnews.com/2019/03/19/its-your-money-conway-plans-buy-morethan-homes-prevent-future-flooding/ [Accessed: 15 December 2020]

Mach KJ, Kraan CM, Hino M, Siders AR, Johnston EM, Field CB (2019) Managed retreat through voluntary buyouts of flood-prone properties. Sci Adv 5(10):eaax8995

Martin C, Gilbert B, Teles D Theodos B (2019) Housing recovery and CDBG-DR: a review of the timing and factors associated with housing activities in HUD's Community Development Block Grant for Disaster Recovery Program. HUD Office of Policy Development and Research

McGinty AA (2017) Home buyouts: one adaptation approach to rising sea levels. Master thesis

Meyer V, Priest S, Kuhlicke C (2012) Economic evaluation of structural and non-structural flood risk management measures: examples from the Mulde River. Nat Hazards 62(2):301-324

Moscovitz AN (2018) Adaptation through acquisition: planning for home buyout and acquisition in the New York Region. Master thesis

Muñoz CE, Tate E (2016) Unequal recovery? Federal resource distribution after a Midwest flood disaster. Int J Environ Res Public Health 13(5)

Nelson KS Camp J (2020) Quantifying the benefits of home buyouts for mitigating flood damages. Anthropocene, p. 100246

NJ Department of Environmental Protection (2015) Frequently asked questions: Superstorm Sandy Blue Acres Buyout Program. NJ Department of Environmental Protection

North, D.C. (1990) Institutions, institutional change, and economic performance. Cambridge University Press

OCLC (2020) WorldCat [Online]. Available at: https://www.worldcat.org/ [Accessed: 21 July 2020]

Peterson K, Apadula E, Salvesen D, Hino M, Kihslinger R, BenDor T (2020) A review of funding mechanisms for US floodplain buyouts. Sustainability

Pinter N (2005) Environment. One step forward, two steps back on U.S. floodplains. Science 308(5719):207-208

Plastrik P Cleveland J (2019) Can it happen here? Improving the prospect for managed retreat by US cities. Innovation Network for Communities

Reidmiller DR, Avery CW, Easterling DR et al (eds) (2018) Impacts, risks, and adaptation in the United States: the fourth National Climate Assessment, volume II. U.S. Global Change Research Program, Washington, DC

Shahab S, Clinch JP, O’Neill E (2018) Estimates of transaction costs in transfer of development rights programs. J Am Plan Assoc 84(1):61-75

Siders AR (2013a) Anatomy of a buyout: New York post-superstorm Sandy. In: Vermont Law School

Siders AR (2013b) Managed coastal retreat: a legal handbook on shifting development away from vulnerable areas. SSRN Electronic Journal

Siders, A.R. 2018 Social justice implications of US managed retreat buyout programs. Climatic Change, pp. 119

Smith R (2014) Cedar Rapids flood buyout is history. The Gazette

Tate E, Strong A, Kraus T, Xiong H (2016) Flood recovery and property acquisition in Cedar Rapids, Iowa. Nat Hazards 80(3):2055-2079

UNC CRC (2018) 2018 seven springs recovery plan. UNC Coastal Resilience Center, Chapel Hill, NC

UNC Institute of the Environment (2016) Case study: Kenosha County, Wisconsin [Online]. Available at: https:// www.eli.org/research-report/case-study-kenosha-county-wisconsin [Accessed: 9 June 2020]

US GAO (2021) FEMA should take additional steps to streamline hazard mitigation grants and assess program effects. United States Government Accountability Office

Weber A. (2019a) Blueprint of a buyout: Blue Acres Program, NJ [Online]. Available at: https://www.nrdc.org/ experts/anna-weber/blueprint-buyout-blue-acres-program-nj [Accessed: 8 June 2020]

Weber A. (2019b) Blueprint of a buyout: Charlotte/Mecklenburg County, NC [Online]. Available at: https:// www.nrdc.org/experts/anna-weber/blueprint-buyout-charlottemecklenburg-county-nc [Accessed: 8 June 2020]

Weber A Moore R (2019) Going under: long wait times for post-flood buyouts leave homeowners under water. Natural Resources Defense Council

Wing OEJ, Bates PD, Smith AM et al (2018) Estimates of present and future flood risk in the conterminous United States. Environ Res Lett 13(3):034023

Zavar E, Hagelman RR (2016). Land use change on US flood plain buyout sites, 1990-2000. Disaster Prevention Manag 25(3):360-74.

Publisher's note Springer Nature remains neutral with regard to jurisdictional claims in published maps and institutional affiliations. 